\title{
Characterization of a Bacteriophage Isolated from a River water against a Local Field Strain Multi-Drug Resistant Staphylococcus Aureus
}

\author{
Akanksha Rai \\ CSIR-NEERI: National Environmental Engineering Research Institute CSIR \\ Krishna Khairnar ( $\sim$ k_khaimar@neeri.res.in ) \\ CSIR-NEERI: National Environmental Engineering Research Institute CSIR https://orcid.org/0000-0002-9674- \\ 0817
}

\section{Research Article}

Keywords: Methicillin-Resistant Staphylococcus aureus, Bacteriophage; Bacteriophage genome sequencing; MultiDrug Resistance.

Posted Date: June 7th, 2021

DOI: https://doi.org/10.21203/rs.3.rs-560231/v1

License: (c) (i) This work is licensed under a Creative Commons Attribution 4.0 International License. Read Full License 


\section{Abstract}

It is becoming increasingly difficult in combating Multi-drug resistant (MDR) bacteria. MDR Staphylococcus aureus particularly methicillin-resistant $S$. aureus is one such notorious pathogen in clinical settings and the food industry. With increasing incidences of drug resistance and slow progress in developing new antibiotics, bacteriophages against pathogenic $S$. aureus are promising as antibacterial. We isolated Four local field MDR $S$. aureus from wastewater samples. We got a bacteriophage against an MDR $S$. aureus from a river-water sample. The bacteriophage was lytic and was stable at various temperatures ranging from $-20^{\circ} \mathrm{C}$ to $37^{\circ} \mathrm{C}$. the bacteriophage was stable at a highly alkaline $\mathrm{P}^{\mathrm{H}}$ and had a narrow host range. Through genomic analysis, the bacteriophage DNA encodes 52 genes, and all predicted genes are on one strand, it also encodes a phage RNA polymerase; although it does not show similarity to any known staphylococcal bacteriophage, it shows similarity (91\%) to Enterobacteriaceae phages. When surveying the research articles about Staphylococcal phages, we could find about the unclassified and Singleton-Staphylococcal phages.

\section{Introduction}

Staphylococcus aureus is a Gram-positive bacterium, it is facultative anaerobe and has a low G+C content DNA. It has a ubiquitous niche and is a common commensal of humans and animals. It colonizes on moist surfaces like nasal passage and axillae (Foster 1996). S. aureus is a successful pathogen, and it can cause severe infections such as skin and soft tissue infection, endocarditis, bacteraemia. It is said that $S$. aureus can infect almost all organs (Wilde et al 2015). The study of this bacterium is important, as it is the leading cause of high morbidity and mortality in hospitals. It has a remarkable tendency to become resistant to all antibiotics coming to clinical use (Kaur et al 2012). Its success as a pathogen is because of the presence of several virulence and resistance genes. $S$. aureus is believed to have one prophage, and most variants even have four prophages (Deghorain and Van 2012). Because of the presence of prophages and pathogenic islands, it gains resistance genes through horizontal gene transfer. And this is a leading cause of evolution in pathogenic $S$. aureus (Deghorain and Van 2012). Dissemination of multi-drug resistant (MDR) S. aureus in the environment is becoming a major concern because of various types of methicillin-resistant $S$. aureus emerging from sources other than hospitals. Thus there are various forms of MRSA based on its origin and molecular typing these are- Hospital-acquired (HAMRSA), Community-acquire (CA-MRSA), and Livestock-acquired (LA-MRSA). Currently, vancomycin-resistant and intermediate $S$. aureus (VRSA and VISA respectively) have also surfaced, vancomycin was until recently available as an option to treat $S$. aureus infection (McGuinness et al 2017). Some effective antibiotics like daptomycin are available to treat a few diseases caused by pathogenic $S$. aureus (Tong et al 2015). The World Health Organization (WHO) has identified several bacterial pathogens including pathogenic MRSA as a leading cause of nosocomial infection, mainly because of inappropriate and irrational use of medicines in health-care and food industries. In the year 2015, WHO introduced an action plan against antimicrobial resistance (https://www.who.int/antimicrobial-resistance/global-action-plan/en/) One of the important focal points was the development of novel antimicrobial products to combat the multidrug-resistant strains. Antibiotics not only cause selective pressure and propagation of resistance genes, but they may be more harmful for example they cause gut dysbiosis and affect mitochondrial functioning. Therefore, an alternative to antibiotics is now being considered. One of the most popular candidates is a bacteriophage (or phage)- viruses that kill bacteria. It was discovered earlier than antibiotics and its effect as antibacterial was also known, but because of antibiotics, it was a less favourable mode of treatment. Now, because of the re-emergence of resistant bacteria, the potential of phage is being re-considered. 
Phages against $S$. aureus are numerous. The percentage of Siphoviridae family phages is largest for $S$. aureus, followed by Myoviridae and only a few Podoviridae family phages are present. Application of Siphoviridae phage is usually not considered owing to its safety concerns as most of them are lysogens. In phage therapy, a highly potent lytic phage is desirable.

Earlier, Staphylococcal phages were used only for typing of $S$. aureus (phage typing) strains and most literature related to its phages is based on its properties which renders $S$. aureus pathogenic, i.e., evolution as a pathogen. $S$. aureus phages were classified earlier on the basis of reaction with polyclonal antibody, and 11 serological groups were identified (Deghorain and Van 2012). In a study done by Kwan et al (2005) on the genomes of 27 S. aureus phages, three classes were identified. In class I, majority of the phages were with small genomes of about $20 \mathrm{Kbp}$, having short non-contractile tail; in class II, phages were with genome size of about 40kbp with long non contractile tail and in class III, phages were with genome size of about $125 \mathrm{kbp}$ with long contractile tails (Deghorain and Van 2012, Kwan et al 2005). In general, the majority of phages belong to the order Caudovirales and in particular $S$. aureus phages belong to Caudovirales (Deghorain and Van 2012). The phages of $S$. aureus have linear double stranded DNA, and based on tail morphology they can be grouped in to three families: Myoviridae, that has long contractile double sheath tail; Siphoviridae, that has long non contractile tail and, Podoviridae, that has small contractile tail (Deghorain and Van 2012). In general, most temperate phages of $S$. aureus belong to the Siphoviridae family, and are considered less important for application based purposes. Phages of $S$. aureus that belong to Myoviridae and Podoviridae family are mostly lytic. These are important for downstream applications because a highly potent lytic phage is desirable as it subverts the essential metabolic pathways of the host (Kwan et al 2005). An updated and comprehensive study on the diversity of Staphylococcal phages has been done by Oliveira et al (2019), they grouped the Staphylococcal phages into four major clusters (A-D clusters) and several sub-clusters.

For application as antimicrobial a thorough genome analysis is essential so that, no resistance or virulence genes and integrase gene are present that may lead to horizontal gene transfer in the host.

In this study, we have isolated few MDR $S$. aureus from the local field samples, and a bacteriophage against it from a river sample; it was named vb_Sau_ARW1 as per the guidelines of International Committee on Taxonomy of Viruses (ICTV), and its physical and genome characteristics were investigated. To get an idea about our work a flow diagram is provided in the figure 1.

\section{Materials And Methods}

All water samples collected through sterile practices. All experiments were done in triplicate. In graphical representations, average value was taken. All cultural media, chemicals and ATCC bacterial strains were purchased from Himedia Labs Pvt. Ltd., Mumbai, India.

\section{Isolation of S. aureus and its phage from water samples}

The process of isolation of $S$. aureus and screening of phage has been discussed in the supplementary file 1 because the full description here in this paper was beyond the limits. In this study we have isolated a phage from a river water sample against the host W1 which is a confirmed local field strain of $S$. aureus and is an MRSA confirmed through antimicrobial susceptibility testing (AST). 


\section{Host Range vb_Sau_ARW1}

The ability of the phage to infect the other bacterial hosts. For this, the following environmental $S$. aureus isolates were taken: W1, W2, W3, W4, E. coli ATCC 23848, S. aureus ATCC 25923, and a lab strain of Enterobacter. $8 \mu \mathrm{L}$ of $0.22 \mu \mathrm{m}$ membrane filtered vb_Sau_ARW1 lysate was added on the host culture plates. If a clear zone appeared on a culture plate, it may indicate phage active against that host. Agar overlay was done to exclude the doubt of lysis due to lysozyme in the lysate. For this, vb_Sau_ARW1 lysate was incubated with isolates mentioned above and kept for overnight incubation at $37^{\circ} \mathrm{C}$ in a rotator incubator and agar overlay was done the next day. In case of ambiguity, such as a faint or turbid plaque, further analysis by picking the plaque and re-incubating it with the host, followed by re-enumeration by double agar overlay.

\section{Partial purification of vb_Sau_ARW1}

Purification of phage is done by picking a single plaque and re-enriching with the host for three consecutive times and precipitated by PEG-NaCl for downstream applications.

For partial purification and concentration of phages (Pickard 2009), ten plates (agar overlay plating method) with dense plaque count was taken, in each plate, $4 \mathrm{ml}$ Phage buffer (P buffer) $\left(10 \mathrm{Mm}\right.$ Tris- $\mathrm{Cl}, 10 \mathrm{mM} \mathrm{MgSO}_{4}, 68 \mathrm{mM}^{2}$ $\mathrm{NaCl}, 1 \mathrm{mM} \mathrm{CaCl}$ constituted in molecular grade water and made up the volume to $1 \mathrm{~L}$ ) was added and kept overnight at $4^{\circ} \mathrm{C}$. After overnight incubation, the lysate was centrifuged at $6000 \mathrm{rpm}$ for $15 \mathrm{~min}$ at $4^{\circ} \mathrm{C}$. The filtrate was then filtered through a $0.22 \mu \mathrm{m}$ membrane filter. In the filtrate RNase A $(20 \mathrm{mg} / \mathrm{ml})$ and DNase $(1 \mathrm{mg} / \mathrm{ml})$ were added such that the final concentration was $4 \mu \mathrm{l} / \mathrm{ml}$. This was kept at $37^{\circ} \mathrm{C}$ for 30 minutes and then kept at room temperature for an additional one hour. Further, for phage precipitation, an ice-cold solution of $40 \% \mathrm{PEG}-\mathrm{NaCl}$ was added (PEG-6000 and $3 \mathrm{M} \mathrm{NaCl}$ ) such that its volume is one-fourth of the total volume of the treated filtered lysate. This was kept at $4^{\circ} \mathrm{C}$ on ice for an hour and then it was centrifuged at $6000 \mathrm{rpm}$ for $40 \mathrm{~min}$ at $4^{\circ} \mathrm{C}$. The precipitate was reconstituted in $0.1 \mathrm{ml}$ of $\mathrm{P}$ buffer. This partially purified phage was kept at $-80^{\circ} \mathrm{C}$ for the next phase of analysis as described below.

\section{Transmission electron microscopy}

TEM analysis was done at the Indian Institute of Technology, Roorkee, India. Sample prepared briefly as- $10 \mu \mathrm{l}$ of the PEG precipitated phage and purified crude lysate was loaded on a copper grid and stained by $10 \mu \mathrm{l}$ of uranyl acetate (Ackermann 2009). Imaging was done at magnification 35000X. (TEM model: Tecnai G2 20)

\section{vb_Sau_ARW1genomic DNA isolation and sequencing}

The partially purified phage is subjected to the phenol-chloroform DNA extraction and ethanol precipitation (Pickard 2009). The precipitate was reconstituted in molecular grade water and was stored at $-20^{\circ} \mathrm{C}$.

Quality of the genomic DNA was checked on $0.8 \%$ agarose gel (loaded $3 \mu \mathrm{l}$ ) for the single intact band. The gel was run at $110 \mathrm{~V}$ for 30 mins. $1 \mu$ l of each sample was used for determining concentration using Qubitß 2.0 Fluorometer.

Sequencing of the phage genomic DNA and analysis of high quality data (HQ) was done at the Xcelris Labs Pvt. Ltd., India. It was sequenced on the Illumina platform with read length 2X 150 PE and coverage of more than 10000. For de novo assembly of the phage, SPAdes version-3.1.0 was used. BLASTn and BLASTx (version 
2.2.28) were done for similarity search for the sequenced phage genome against the non-redundant protein database.

For reference based approach, reference phage genomes were downloaded from EMBI-EBI https://www.ebi.ac.uk/genomes/phage.html. There were total of 2401 phage genomes from which 104 genomes were representing $S$. aureus. HQ data were mapped with the reference phage genomes using CLC genomic workbench.

Genes prediction was done through Prodigal version 2.6.3 (Hyatt et al 2010). The phage lifecycle prediction was done through PHACTS (McNair et al 2012), a web tool (https://edwards.sdsu.edu/PHACTS/). Presence or absence of tRNA genes was done through a web-based tool called tRNAscan-SE (http://Lowelab.usu.edu/tRNASCAN-SE/) (Lowe and Chan 2016). For identification of antimicrobial resistance genes 'Resistance Gene Identifier' (RGI), a web based tool was used (https://card.mcmaster.ca/analyze/rgi) [17] (Alcock et al 2020).

$\mathrm{HQ}$ data is submitted in SRA submissions (in NCBI), submission ID is shared in the result section.

\section{Adsorption Rate}

For the determination of adsorption rate Kropinski (2009), Kaur et al. (2012) were considered. $9 \mathrm{ml}$ of exponentially growing $S$. aureus (W1) culture of optical density at $600 \mathrm{~nm}(\mathrm{OD} 600) 0.2 \mathrm{OD}\left(10^{8} \mathrm{CFU} / \mathrm{ml}\right) \mathrm{was}$ taken in a $100 \mathrm{ml}$ flask, to this $1 \mathrm{ml}$ of pre-warmed phage suspension of titre $1 * 10^{5} \mathrm{PFU} / \mathrm{ml}$ was added. At time zero, $100 \mu \mathrm{l}$ aliquot was withdrawn and added to $900 \mu \mathrm{l}$ fresh broth (kept in $2 \mathrm{ml}$ Eppendorf tube), thereafter at regular interval of $1.5 \mathrm{~min}$., this process was repeated till $10 \mathrm{~min}$. These aliquots were centrifuged at $14000 \mathrm{rpm}$ for 15 min., the supernatant was carefully withdrawn and mixed with fresh host broth culture for phage enumeration. The amount of phage adsorbed to the host cell was determined as a decrease in the titer of free phage. Refer to table 1 . Adsorption rate $\left(k_{a}\right)$ was calculated with following mathematical formula $k_{a}=$ $(2.3 / \mathrm{Bt}){ }^{*} \log \left(P_{0} / P\right)$, here $B$ is host concentration, $t$ is time taken for decrease in the plaque counts from initial, $P_{0}$ to the final plaque count, $P$.

\section{One step growth}

For one step growth, methods by Ellis and Delbruck (1939), Hyman and Abedon (2009) were followed. $1 \mathrm{ml}$ of phage at a $\mathrm{MOI}$ of 0.1 was added in $9 \mathrm{ml}$ of exponentially growing $S$. aureus culture (similar to adsorption rate method) and allowed to adsorb completely on $S$. aureus for $8 \mathrm{~min}$, this was centrifuged at $6000 \mathrm{rpm}$ for $10 \mathrm{~min}$. This pellet was suspended in $10 \mathrm{ml}$ broth. After every 5 minutes, $100 \mu \mathrm{l}$ of the aliquot was taken and added in $900 \mu \mathrm{l}$ broth and plated by agar overlay method. An average value of five independent experiments was taken.

\section{Phage viability}

Viability of vb_Sau_ARW1 for a period of one year was tested. Filtered phage stocks were kept in the P buffer. Their viability was tested at temperatures ranging from $-20^{\circ} \mathrm{C}, 4^{\circ} \mathrm{C}, 25^{\circ} \mathrm{C}, 40^{\circ} \mathrm{C}$, and $60^{\circ} \mathrm{C}$. Survivability of phage was studied at different $\mathrm{P}^{\mathrm{H}}$ : in the $9 \mathrm{ml}$ of $\mathrm{P}$ buffer of different $\mathrm{P}^{\mathrm{H}}$ was prepared; that is., $\mathrm{P}^{\mathrm{H}}$ of $2,4,6,8,10$, and 12 to this $1 \mathrm{ml}$ of phage suspension was added and kept at $37^{\circ} \mathrm{C}$ for overnight incubation. $100 \mu \mathrm{l}$ of sample was taken from each tube and mixed with $100 \mu$ of actively growing host, and agar-overlay was done on this mixture for phage enumeration. 


\section{Results}

\section{Isolation of vb_Sau_ARW1 and identification through TEM}

We got a phage against $S$. aureus (W1 isolate) from a water sample of the River Ganga, but in low titre of $38 \mathrm{PFU} / \mathrm{ml}$ (please refer to the supplementary file 1). The TEM image of the phage is shown in Fig. 2. The image suggests a phage that belongs to the order Caudovirales and Podoviridae family, which has a typical icosahedral geometry of capsid and a short stubby tail.

\section{Discussion}

Both genomic and TEM analysis are in accordance with each other that our phage vb_Sau_ARW1 has characteristics of order Caudovirales, family Podoviridae. Like a typical phage it has a modular genome organization (Fig. 3), means the genes are present in a particular order in which its transcription and replication is necessary. It can be inferred from the de novo and reference based approach the phage shows similarity to Klebsiella phages of the family Podoviridae and sub-family Autographivirinae, vb_Sau_ARW1 genome has a RNA polymerase, and all the predicted genes are encoded on minus strand, this is typical feature the sub-family Autographivirinae, a few other phages of this sub-family are T7, SP6 (King et al 2011). Contrary to the usual Staphylococcal phages, vb_Sau_ARW1 does not show similarity to the known S. aureus phages. Since phages have highly mosaic genomes (Deghorain and Van 2012, Oliveira et al 2019), thus an anomaly may be expected. It must be noted here that the location of isolation of the host and vb_Sau_ARW1 are different, that may contribute to this anomaly. Also, there are some unassigned/unclassified phages of $S$. aureus for example, PT1028, it has ds DNA genome of around 20Kbp and has unknown morphology. P954 and ROSA are unassigned phages of unknown morphologies, both have ds DNA genome of size $40 \mathrm{kbp}$, but these two show similarity to $S$. aureus phages of the family Siphoviridae (Oliveira et al 2019, King et al 2011). The singleton SPbeta-like phage is a Siphoviridae phage that shows less than $10 \%$ similarity to any known Staphylococcal phage, its lysogeny module is non-functional (Oliveira et al 2019).

Regarding the phage physical parameters, the survival was assessed by placing it in different temperatures and $\mathrm{P}^{\mathrm{H}}$. The most optimum condition for its activity is at room temperature and at $\mathrm{P}^{\mathrm{H}}$ within a range of 7-8. Like most phages, vb_Sau_ARW1 was found to be stable at alkaline condition but was inactivated in acidic conditions, but the size of the plaque (zone of lysis) decreased in highly alkaline $\mathrm{P}^{\mathrm{H}}$. The phage was stable at various temperatures $\left(-20^{\circ} \mathrm{C}, 4^{\circ} \mathrm{C}, 25^{\circ} \mathrm{C}\right.$ and $\left.37^{\circ} \mathrm{C}\right)$, but above $40^{\circ} \mathrm{C}$ phage titre dropped sharply. The phage remained viable at $-20^{\circ} \mathrm{C}$ for the entire period of this study (for three years). The phage was also active for a month at $4^{\circ} \mathrm{C}$, its titre did not diminish significantly. We found that this phage has a short adsorption rate, high burst size, and short latency period (the time interval between adsorption and appearance of the first burst of phage progeny). Some example of S. aureus phages with short latency period are phage SPW (a Myoviridae phage) and phage SLPW (a Podoviridae phage (Li and Zhang 2014, Wang et al 2016). It should be noted that both latent period and burst size depend on the host cell, infecting phage, and the incubation conditions (Sinha et al 2018). Thus this indicates that it is a good candidate for biocontrol as it can quickly adsorb and kill the host.

In totality the results of the phage physical and genomics characteristics, particularly the host range where it is not infecting any Gram-negative isolates i.e. E. coli ATCC 23848 and Enterobacter but produces faint plaques with some $S$. aureus isolates, a faint plaque is an indicator of a lysogeny (Hyman 2019), however, no genes related to 
lysogeny was predicted, also the PHACTs tool predicts that it follows a lytic lifecycle. The $\mathrm{G}+\mathrm{C}$ content of the phage genome is not in accordance with the usual Staphylococcal phages. Here, we do not emphasize that it is a Staphylococcal phage but an atypical phage which has genomic features of phages of Gram-negative groups but it infects Staphylococcal isolates. What makes this phage divergent or is it a phage from Enterobacteriaceae group capable of infecting divergent bacterial species is an interesting topic and warrants further research. Overall, this research contributes to the phage genomics that may be useful in understanding phage evolution. The genomic data also opens prospects of phage based antimicrobial peptides.

\section{Declarations}

Ethical Approval and Consent to Participate: Not applicable

Consent for Publication: Not applicable

Availability of Data and Material: Phage vb_Sau_ARW1 genomic DNA sequencing data is deposited at the GenBank (SRA submission ID: PRJNA637459). 16S rRNA sequencing data of the MDR S. aureus (W1 isolate) deposited at the GenBank, submission ID: MN078268.

Competing Interest: Akanksha Rai and Krishna Khairnar declare that they have no conflict of interest.

Funding: The research was supported by the National Mission for Clean Ganga (NMCG, GAP-2103). Akanksha Rai received a financial assistance as fellowship from the University Grants Commission (UGC), India.

Author's Contributions: Conceptualization: Krishna Khairnar and Akanksha Rai; Methodology: Akanksha Rai; Investigation: Akanksha Rai; Writing- original draft preparation: Akanksha Rai; Writing- review and editing: Krishna Khairnar and Akanksha Rai; Supervision: Krishna Khairnar.

Acknowledgements: We are thankful to Environmental Virology Cell, CSIR-NEERI, Nagpur and Director CSIR-NEERI for providing the research facility and infrastructure. We are thankful for the funding from National Mission for Clean Ganga (NMCG, GAP-2103). Financial assistance to Akanksha Rai in form of fellowship from the University Grants Commission (UGC), India is gratefully acknowledged. We are grateful to the Department of Biotechnology, IIT-Roorkee, India, for assistance in TEM.

Authors' Information: Akanksha Rai is a Senior Research Fellow at the Environmental Virology Cell, Council of Scientific and Industrial Research-National Environmental Engineering Research Institute (CSIR NEERI), Nehru Marg, Nagpur, Maharashtra, India. Akanksha Rai is also a doctoral student registered at the Academy of Scientific and Innovative Research (AcSIR) Ghaziabad, Uttar Pradesh, India. Krishna Khairnar is a Senior Scientist and Head of the Environmental Virology Cell, Council of Scientific and Industrial Research-National Environmental Engineering Research Institute (CSIR NEERI), Nehru Marg, Nagpur, Maharashtra, India.

\section{References}

1. Ackermann H.W. (2009) Basic phage electron microscopy. Methods Mol Biol 501: 113-126. https://doi.org/10.1007/978-1-60327-164-6_12

2. Alcock BP, Raphenya AR, Lau TT, Tsang KK, Bouchard M, Edalatmand A, Huynh W, Nguyen ALV, Cheng AA, Liu S and Min SY (2020). CARD 2020: antibiotic resistome surveillance with the comprehensive antibiotic 
resistance database. Nucleic Acids Res 48(D1): D517-D525. https://dx.doi.org/10.1093\%2Fnar\%2Fgkz935

3. Carver T, Thomson N, Bleasby A, Berriman M and Parkhill J (2009) DNAPlotter: circular and linear interactive genome visualization. Bioinformatics, 25(1):119-120. doi: 10.1093/bioinformatics/btn578.

4. Deghorain M and Van ML (2012) The Staphylococci phages family: an overview. Viruses 23: 3316-35. https://dx.doi.org/10.3390\%2Fv4123316

5. Ellis EL and Delbrück M (1939) The growth of bacteriophage. J Gen Physiol 22: 365-384. https://dx.doi.org/10.1085\%2Fjgp.22.3.365

6. Foster T (1996) Staphylococcus. Medical Microbiology, $4^{\text {th }}$; Baron S. Galveston (TX): University of Texas Medical Branch at Galveston. Chapter12.PMID: 21413338

7. Hyatt D, Chen GL, Locascio PF, Land ML, Larimer FW and Hauser LJ (2010) Prodigal: prokaryotic gene recognition and translation initiation site identification. BMC bioinformatics 11: 119. https://doi.org/10.1186/1471-2105-11-119

8. Hyman, P. and Abedon S.T. (2009) Practical methods for determining phage growth parameters. Methods Mol Biol 501: 175-202. https://doi.org/10.1007/978-1-60327-164-6_18

9. Kaur S, Harjai K, and Chhibber S (2012) Methicillin-resistant Staphylococcus aureus phage plaque size enhancement using sublethal concentrations of antibiotics. Appl Environ Microbiol 78(23): 8227-8233. https://dx.doi.org/10.1128\%2FAEM.02371-12

10. King, A.M., Lefkowitz, E., Adams, M.J. and Carstens, E.B. eds., (2011) Virus taxonomy: ninth report of the International Committee on Taxonomy of Viruses(Vol. 9). Elsevier.https://doi.org/10.1016/B978-0-12384684-6.00105-1

11. Kropinski AM (2009) Measurement of the rate of attachment of bacteriophage to cells. Bacteriophages Methods and Protocols, Isolation, Characterization, and Interactions, $1^{\text {st }}$, Clokie, M.R. and Kropinski, A.M Humana press: New York city, United States, Volume 1,.151-155. 10.1007/978-1-60327-164-6

12. Kwan T, Liu J, DuBow M, Gros P, Pelletier J (2005) The complete genomes and proteomes of 27 Staphylococcus aureus Proc Natl Acad Sci USA 102(14):5174-5179. https://doi.org/10.1073/pnas.0501140102

13. Li, L. and Zhang, Z., (2014) Isolation and characterization of a virulent bacteriophage SPW specific for Staphylococcus aureus isolated from bovine mastitis of lactating dairy cattle. Mol Biol Rep 41(9):5829-5838. https://doi.org/10.1007/s11033-014-3457-2

14. Lowe TM and Chan PP (2016). tRNAscan-SE On-line: integrating search and context for analysis of transfer RNA genes. Nucleic acids res 44(W1): W54-W57. https://doi.org/10.1093/nar/gkw413

15. McGuinness WA, Malachowa N and DeLeo FR (2017) Focus: infectious diseases: vancomycin resistance in Staphylococcus aureus. YJBM 90: 269. https://www.ncbi.nlm.nih.gov/pubmed/28656013

16. McNair K, Bailey BA, Edwards RA (2012) PHACTS, a computational approach to classifying the lifestyle of phages. Bioinformatics 28(5): 614-618. https://doi.org/10.1093/bioinformatics/bts014

17. Oliveira H, Sampaio M, Melo LD, Dias O, Pope WH, Hatfull GF and Azeredo J (2019) Staphylococci phages display vast genomic diversity and evolutionary relationships. BMC genomics, 20(1):357.

https://doi.org/10.1186/s12864-019-5647-8

18. Pickard DJJ (2009) Preperation of bacteriophage lysate and pure DNA. Bacteriophages: Methods and Protocols, Molecular and Applied Aspects, $1^{\text {st }}$, Clokie, M.R. and Kropinski, A.M Humana press: New York city, 
United States Volume 2. 10.1007/978-1-60327-565-1

19. Sinha S., Grewal, R.K. and Roy, S., (2018) Modeling Bacteria-Phage Interactions and Its Implications for Phage Therapy. Adv Appl Microbiol 103: 103-141. 10.1016/bs.aambs.2018.01.005

20. Tong SY, Davis JS, Eichenberger E, Holland TL, and Fowler VG (2015) Staphylococcus aureus infections: epidemiology, pathophysiology, clinical manifestations, and management. Clin Microbiol Rev 28(3): 603-661. 1128/CMR.00134-14

21. Wang Z, Zheng P, Ji W, Fu Q, Wang H, Yan Y, and Sun J (2016) SLPW: a virulent bacteriophage targeting methicillin-resistant Staphylococcus aureus in vitro and in vivo. Front Microbio 7:934. https://doi.org/10.3389/fmicb.2016.00934

22. WHO (2020) Global action plan on AMR https://www.who.int/antimicrobial-resistance/global-action-plan/en/ accessed 29 January 2020.

23. Wilde AD, Snyder DJ, Putnam NE, Valentino MD, Hammer ND, Lonergan ZR, Hinger SA, Aysanoa EE, Blanchard C, Dunman PM and Wasserman GA (2015) Bacterial hypoxic responses revealed as critical determinants of the host-pathogen outcome by TnSeq analysis of Staphylococcus aureus invasive infection. PLoS pathog 11(12). http://doi.org/10.1371/journal.ppat.1005341

24. Hyman P (2019) Phages for Phage Therapy: Isolation, Characterization, and Host Range Breadth. Pharmaceuticals 2(1):35. doi: 10.3390/ph12010035. PMID: 30862020; PMCID: PMC6469166.

\section{Tables}

Table 1: Phage Adsorption Assay. Pt', initial concentration of phage; Pt, concentration of phage at a given time.

\begin{tabular}{|c|c|c|c|}
\hline S.No. & $\begin{array}{l}\text { Time in } \\
\text { min. }\end{array}$ & $\begin{array}{l}\text { Average value of plaque forming unit } \\
\text { (as PFU/ml) }\end{array}$ & $\begin{array}{l}\text { Free Phage (Unadsorbed) (in percent values) = } \\
{\left[\left(\mathrm{Pt}^{\prime}-\mathrm{Pt}^{\prime}\right) / \mathrm{Pt}^{\prime}\right] * 100}\end{array}$ \\
\hline 1 & 0 & 157 & 100 \\
\hline 2 & 1.5 & 28 & 17.9 \\
\hline 3 & 3 & 22 & 14.1 \\
\hline 4 & 4.5 & 12 & 7.7 \\
\hline 5 & 6 & 9 & 5.8 \\
\hline 6 & 7.5 & 1 & 0.7 \\
\hline 7 & 9 & 0 & 0 \\
\hline
\end{tabular}

Table 2: Host range study of the isolated phage with local field isolates of Staphylococcus and a representative of Gram-positive bacteria, Gram-negative bacteria ATCC cultures, and a lab isolate of Enterobacter 


\begin{tabular}{|c|c|c|c|c|c|c|c|}
\hline $\begin{array}{l}\text { Isolates/host } \rightarrow \\
\text { vb_Sau_ARW1 } \\
\downarrow\end{array}$ & $\begin{array}{l}\text { W1 or } \\
\text { S } \\
\text { aureus }\end{array}$ & W2 & W3 & W4 & $\begin{array}{l}\text { S. } \\
\text { aureus } \\
\text { ATCC } \\
25923\end{array}$ & $\begin{array}{l}E . \\
\text { coli } \\
\text { ATCC } \\
23848\end{array}$ & Enterobacter \\
\hline Spot assay & yes & yes & yes & yes & yes & nil & nil \\
\hline Agar overlay & clear & faint & faint & faint & faint & nil & nil \\
\hline $\begin{array}{l}\text { Agar overlay } \\
\text { with plaque } \\
\text { purified phage }\end{array}$ & clear & nil & nil & nil & nil & nil & nil \\
\hline
\end{tabular}

\section{Figures}

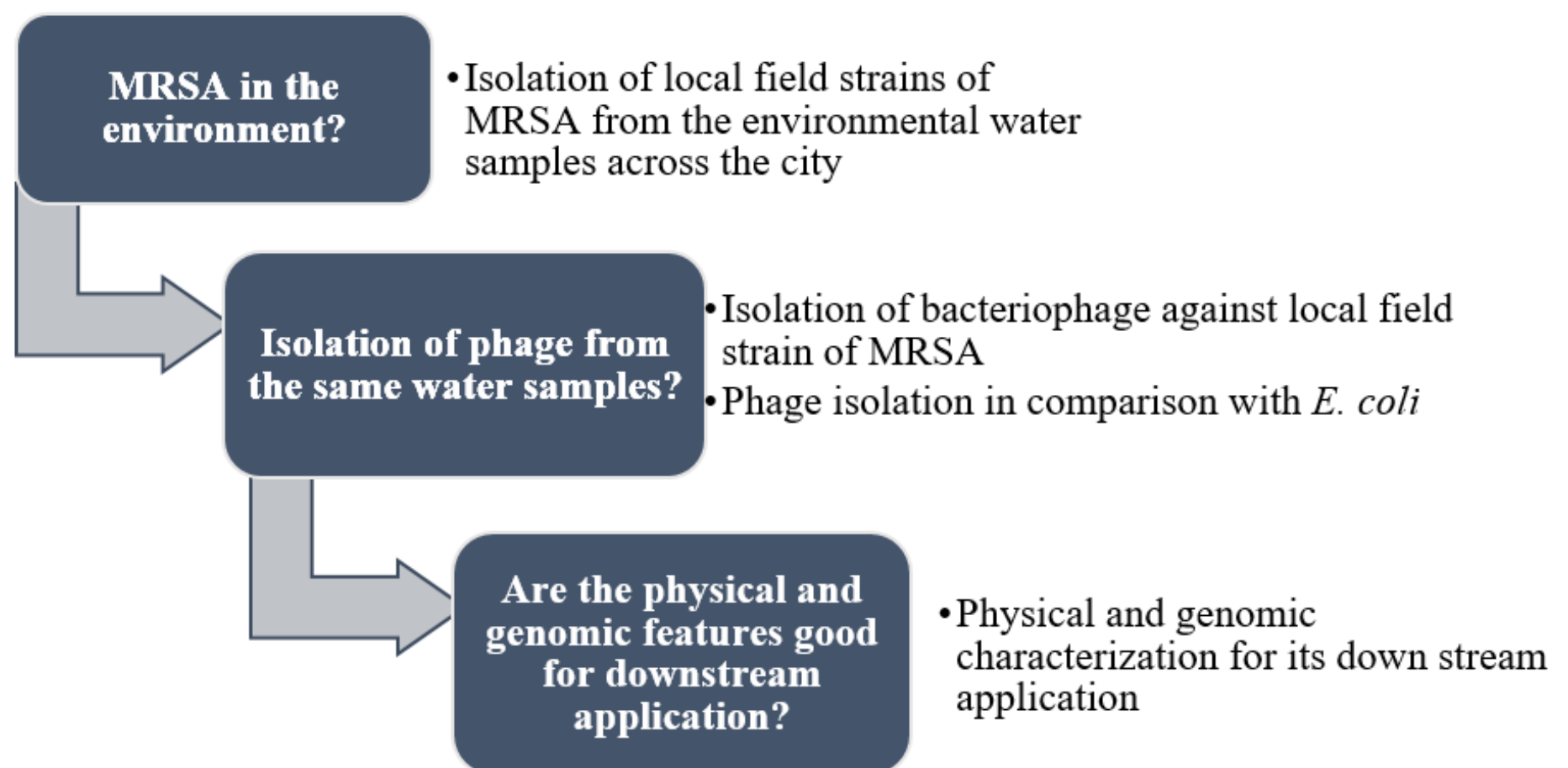

Figure 1

A flow diagram depicting the work-plan of our research, please note that the description about the isolation of $\mathrm{S}$. aureus and phage is given in the supplementary file 1. 


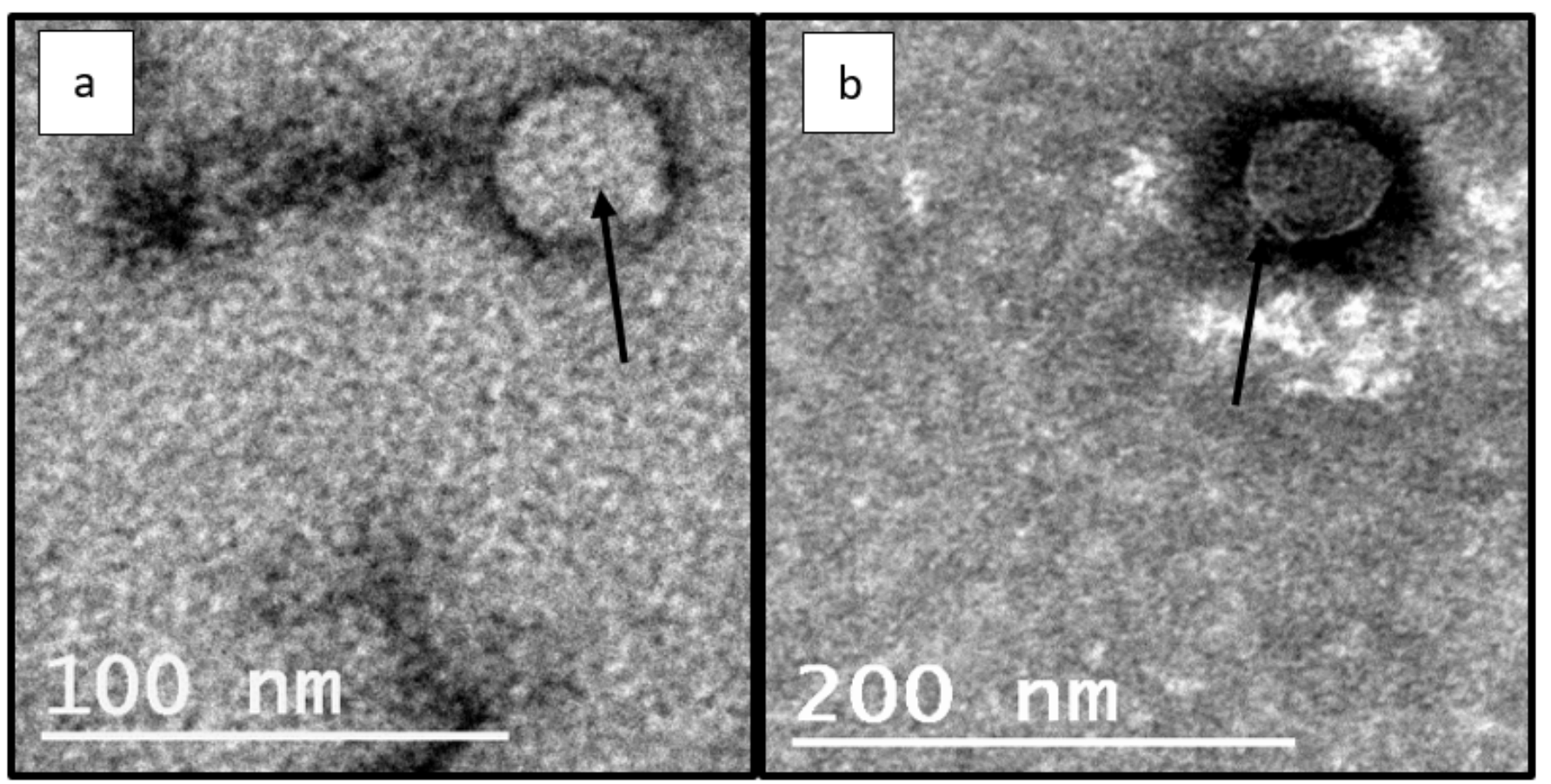

\section{Figure 2}

TEM images of the phage vb_Sau_ARW1 at different magnifications, a, PEG-NaCl purified phage shows clear capsid, b, Crude lysate shows the phage with a stubby tail (arrow shows phage particle, at magnification 35000X). 

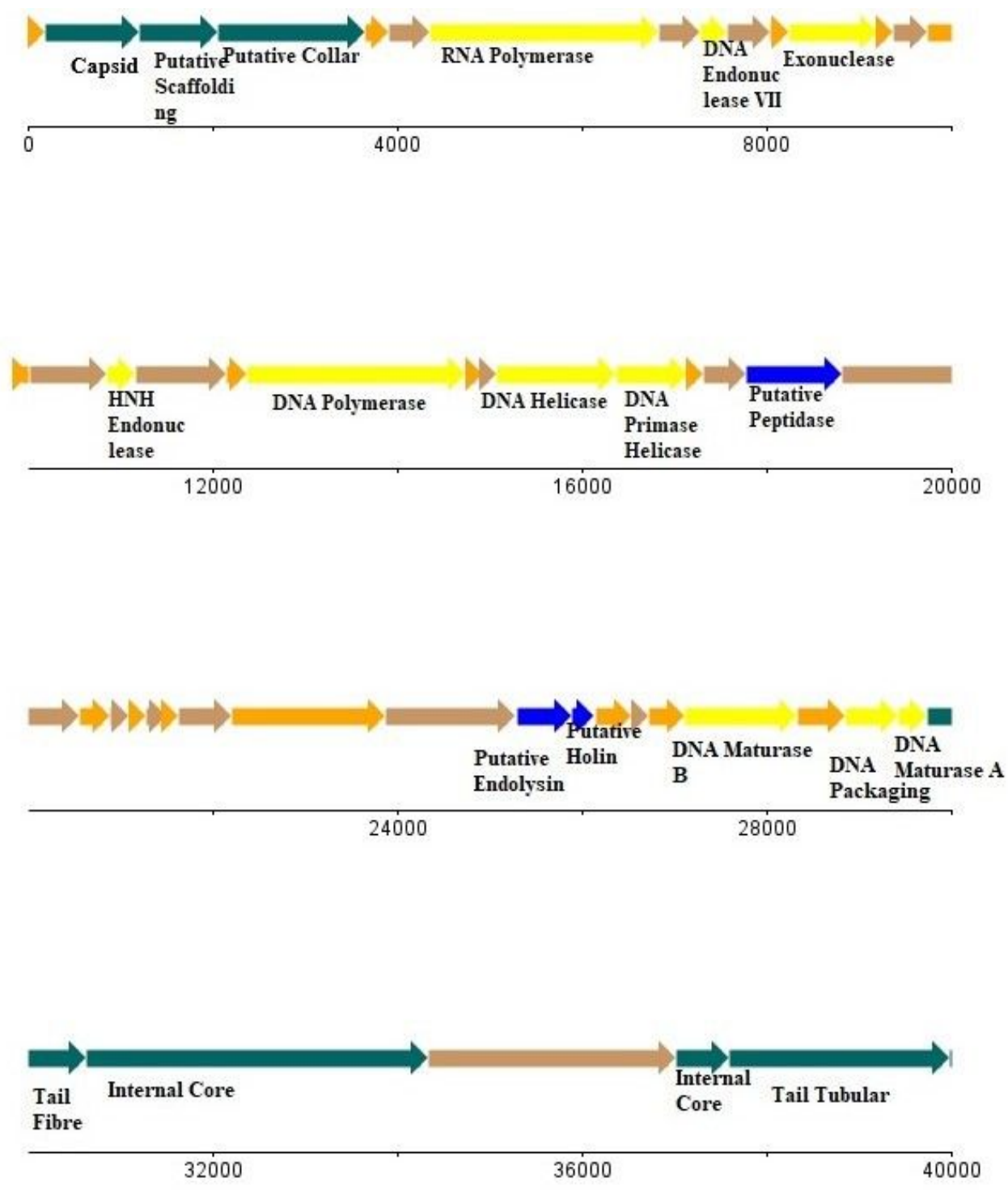

\section{Figure 3}

A linear map of vb_Sau_ARW1 genome. Genes were predicted through Prodigal (Plotted on the software DNA Plotter). 

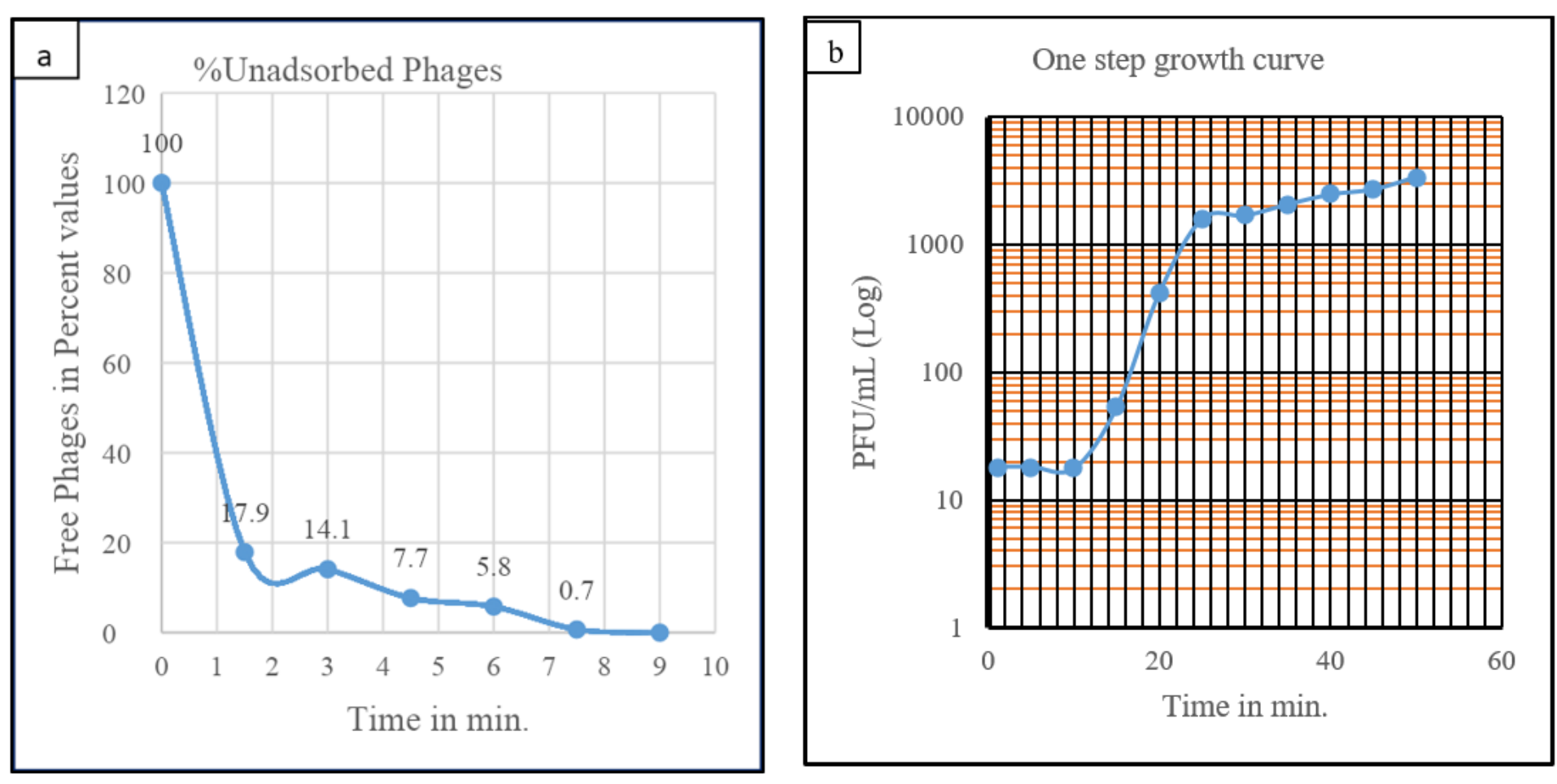

Figure 4

4a: Graph of adsorption assay of the phage determined in terms of percent free-phages; $4 \mathrm{~b}$ : Graph of the growth curve of vb_Sau_ARW1.

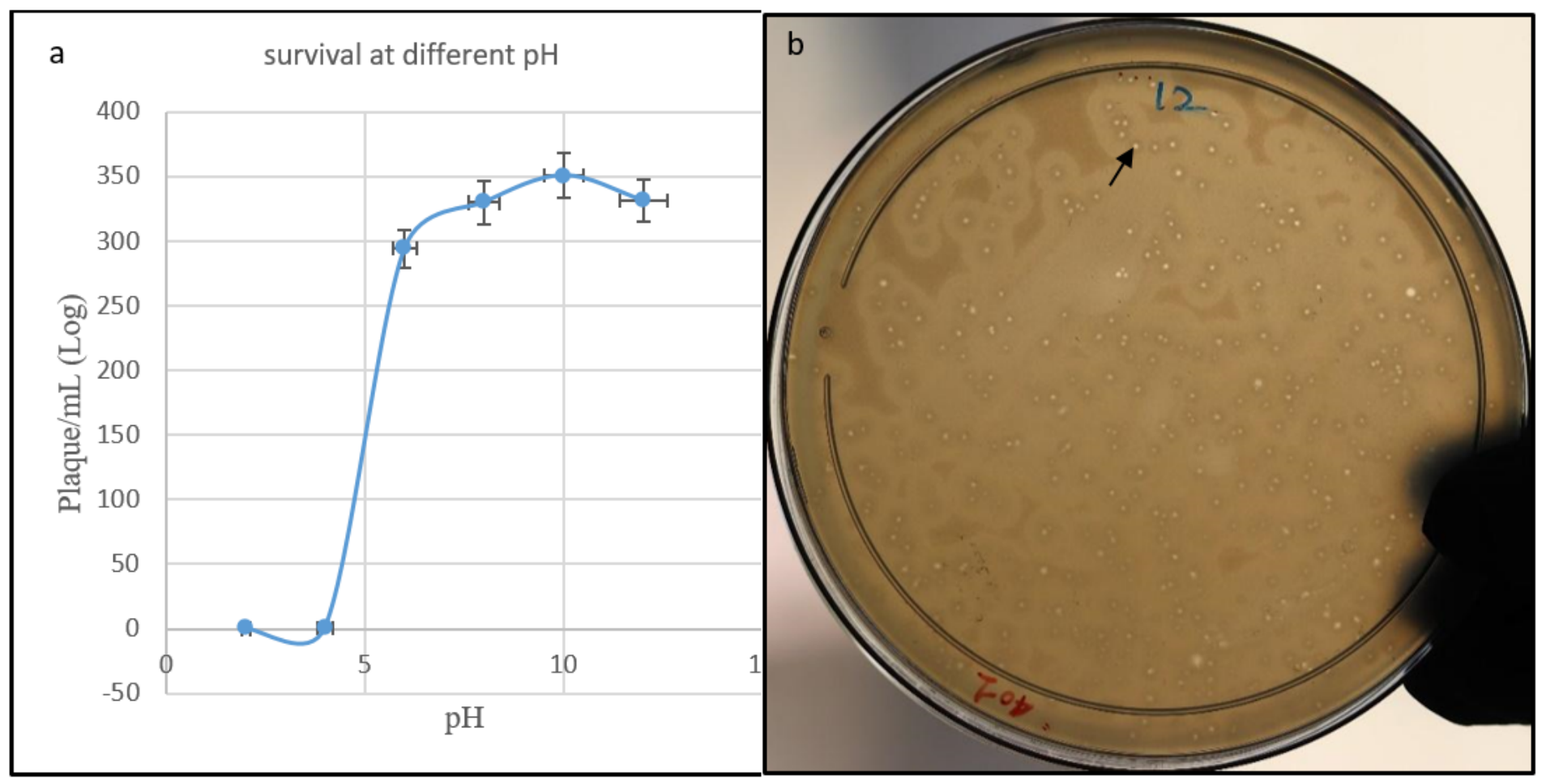

Figure 5

5a: Graph representing the phage survival at different acidity and basicity; $5 \mathrm{~b}$ : A plaque assay plate showing considerable decrease in the plaque size in the acidic medium. 


\section{Supplementary Files}

This is a list of supplementary files associated with this preprint. Click to download.

- Supplementary1highlightingthephenomenon16.04.2021.docx

- ARSupplementary2.docx 